\title{
Effect of Exogenous Hormones and Reproductive Factors in Female Melanoma: A Meta-Analysis [Letter]
}

\author{
Manuela Chiavarini ${ }^{1}$, Giulia Naldini ${ }^{2}$, Irene Giacchetta $\mathbb{D}^{2}$, Roberto Fabiani ${ }^{3}$ \\ 'Department of Medicine and Surgery, Section of Public Health, University of Perugia, Perugia, Italy; ${ }^{2}$ School of Specialization in Hygiene and \\ Preventive Medicine, University of Perugia, Perugia, Italy; ${ }^{3}$ Department of Chemistry, Biology and Biotechnology, University of Perugia, Perugia, Italy \\ Correspondence: Irene Giacchetta, University of Perugia, Tel +39 35I52255I4, Email irene.giacchetta@gmail.com; irene.giacchetta@studenti.unipg.it
}

\section{Dear editor}

I read with interest the meta-analysis of Sun et al., ${ }^{1}$ but while their results can be partly true, the article's screening and selection were critical. The meta-analysis, in fact, did not include ten articles (including three large cohort studies), without reporting any reason for exclusion.

The following are the manuscripts not included by Sun et al.: ${ }^{1}$

1. Botteri et al., ${ }^{2}$ which is a nationwide register-based, cohort study of 293,570 women; it studied the risk of Melanoma associated with menopausal hormone therapy (MHT). Botteri used SIR as the risk measure, which is an exclusion criterion of Sun et al., ${ }^{1}$ but $\mathrm{OR} / \mathrm{RR} / \mathrm{HR}$ could have been calculated.

2. Brinton et al., ${ }^{3}$ which is a large cohort study of 9,892 women that studied the risk of Melanoma associated with MHT and with oral contraceptives (OC).

3. Behrens et al., ${ }^{4}$ which is a case-control study. It studied the risk of Uveal Melanoma associated with OC and MHT.

4. Vessey et al., ${ }^{5}$ which is a cohort study, that considered 17,032 women, between 25 and 39 years old. It studied the risk of Melanoma associated with OC.

5. Hannaford et al., ${ }^{6}$ which is a large cohort study, that considered more than 60,000 women between 25 and 39 years old. It studied the risk of Melanoma associated with OC.

6. Holly et al., ${ }^{7}$ a case-control study which examined MHT/OC and risk of uveal melanoma.

7. Hartge et al., ${ }^{8}$ a case-control study which studied the association between MHT/OC and intraocular malignant melanoma.

8. Gallagher et al., ${ }^{9}$ which is a case-control study. It studied the risk of Melanoma associated with OC.

9. Green et al., ${ }^{10}$ which is a case-control study. It studied the risk of Melanoma associated with OC.

10. Kay et al., ${ }^{11}$ a cohort study, which examined the association between OC and risk of Melanoma.

Therefore, among the studies above, the risk of Melanoma associated with OC was analysed by: Brinton et al., ${ }^{3}$ Behrens et al., ${ }^{4}$ Vessey et al., ${ }^{5}$ Hannaford et al., ${ }^{6}$ Holly et al., ${ }^{7}$ Hartge et al., ${ }^{8}$ Gallager et al., ${ }^{9}$ Green and Bain, ${ }^{10}$ Kay et al.., ${ }^{11}$ whereas the risk of Melanoma associated with MHT was analysed by: Botteri et al., ${ }^{2}$ Brinton et al., ${ }^{3}$ Behrens et al., ${ }^{4}$ Holly et al., ${ }^{7}$ Hartge et al. ${ }^{8}$

Moreover, three studies could also have been considered for analysis of the duration of OC use and female Melanoma risk: Hannaford et al., ${ }^{6}$ Gallagher et al., ${ }^{9}$ Green and Bain. ${ }^{10}$

Finally, considering the articles included by Sun et al., ${ }^{1}$ and the exclusion criteria chosen by the authors, Mueller et al. ${ }^{12}$ should not have been accepted because it is a letter to the editor. 
Considering the articles mentioned above, we performed a new meta-analysis on the risk of OC/MHT and Cutaneous Malignant Melanoma (CMM).

Our results showed a combined pooled risk of CMM in OC users of $1.03(0.95-1.12)$ with low heterogeneity (I2 = $33.6 \%)$ : in cohort study $1.07(1.00-1.15)$, in case-control study $1.00(0.87-1.16)$, all with a shorter confidence Interval (pooled: $0.99(0.90-1.10)$; cohort study $1.06(0.98-1.14)$; case-control study $0.98(0.83-1.15))$ and smaller heterogeneity (I2 $=54 \%$ ) than Sun et al. ${ }^{1}$

Our results showed a combined pooled risk of CMM in MHT users of 1.17 (1.09-1.26) with low heterogeneity (I2 $=27.8 \%)$ : with a shorter confidence interval of $1.12(1.02-1.24)$ and smaller heterogeneity $(\mathrm{I} 2=50 \%)$ than Sun et al. ${ }^{1}$

Concluding, the meta-analysis by Sun was carried out with an incorrect methodology, which, if on one hand does not excessively alter the results, on the other hand it invalidates them since, as PRISMA teaches, the methodology is central in revisions and meta-analyses.

Looking forward your answer, we hope you would consider our observations.

\title{
Disclosure
}

The authors report no conflicts of interest in this communication.

\section{References}

1. Sun Q, Sun H, Cong L, Zheng Y, Wu N, Cong X. Effects of exogenous hormones and reproductive factors on female melanoma: a meta-analysis. Clin Epidemiol. 2020;12:1183-1203. PMID: 33149695; PMCID: PMC7605627. doi:10.2147/CLEP.S273566

2. Botteri E, Støer NC, Weiderpass E, Pukkala E, Ylikorkala O, Lyytinen H. Menopausal hormone therapy and risk of melanoma: a nationwide register-based study in Finland. Cancer Epidemiol Biomarkers Prev. 2019;28(11):1857-1860. doi:10.1158/1055-9965.EPI-19-0554

3. Brinton LA, Moghissi KS, Scoccia B, et al. Effects of fertility drugs on cancers other than breast and gynecologic malignancies. Fertil Steril. 2015;104(4):980-988. doi:10.1016/j.fertnstert.2015.06.045

4. Behrens T, Kaerlev L, Cree I, et al. Hormonal exposures and the risk of uveal melanoma. Cancer Causes Control. 2010;21(10):1625-1634. doi:10.1007/s10552-010-9591-9

5. Vessey MP, Painter R, Powell J. Skin disorders in relation to oral contraception and other factors, including age, social class, smoking and body mass index. Findings in a large cohort study. Br J Dermatol. 2000;143(4):815-820. doi:10.1046/j.1365-2133.2000.03782.x

6. Hannaford PC, Villard-Mackintosh L, Vessey MP, Kay CR. Oral contraceptives and malignant melanoma. Br J Cancer. 1991;63(3):430. doi:10.1038/bjc.1991.99

7. Holly EA, Aston DA, Ahn DK, Kristiansen JJ. Uveal melanoma, hormonal and reproductive factors in women. Cancer Res. 1991;51(5):13701372.

8. Hartge P, Tucker MA, Shields JA, Augsburger J, Hoover RN, Fraumeni JF. Case-control study of female hormones and eye melanoma. Cancer Res. 1989;49(16):4622-4625.

9. Gallagher RP, Elwood JM, Hill GB. Risk factors for cutaneous malignant melanoma: the Western Canada Melanoma Study. Recent Results Cancer Res. 1986;102:38-55. doi:10.1007/978-3-642-82641-2_4

10. Green A, Bain C. Hormonal factors and melanoma in women. Med J Aust. 1985;142(8):446-448. doi:10.5694/j.1326-5377.1985.tb113446.x

11. Kay CR. Malignant melanoma and oral contraceptives. Br J Cancer. 1981;44(3):479. doi:10.1038/bjc.1981.211

12. Mueller K, Verzi AE, Bhatt K, et al. Melanoma and chronic exposure to contraceptives containing microdoses of ethinylestradiol in young women: a retrospective study from the Research on Adverse Drug Events and Reports (RADAR) project comprising a large Midwestern U.S. patient population. J Eur Acad Dermatol Venereol. 2018;32(3):e87-e88. PMID: 28833586. doi:10.1111/jdv.14534

\begin{abstract}
Dove Medical Press encourages responsible, free and frank academic debate. The content of the Clinical Epidemiology 'letters to the editor' section does not necessarily represent the views of Dove Medical Press, its officers, agents, employees, related entities or the Clinical Epidemiology editors. While all reasonable steps have been taken to confirm the content of each letter, Dove Medical Press accepts no liability in respect of the content of any letter, nor is it responsible for the content and accuracy of any letter to the editor.
\end{abstract}

Clinical Epidemiology

\section{Dovepress}

\section{Publish your work in this journal}

Clinical Epidemiology is an international, peer-reviewed, open access, online journal focusing on disease and drug epidemiology, identification of risk factors and screening procedures to develop optimal preventative initiatives and programs. Specific topics include: diagnosis, prognosis, treatment, screening, prevention, risk factor modification, systematic reviews, risk \& safety of medical interventions, epidemiology \& biostatistical methods, and evaluation of guidelines, translational medicine, health policies \& economic evaluations. The manuscript management system is completely online and includes a very quick and fair peer-review system, which is all easy to use.

Submit your manuscript here: https://www.dovepress.com/clinical-epidemiology-journal

https://doi.org// $0.2147 /$ CLEP.S356205 